

\title{
14 N Nuclear quadrupole coupling and methyl internal rotation in the microwave spectrum of 2-methylpyrrole
}

Thuy Nguyen, Christina Dindic, Wolfgang Stahl, Ha Vinh Lam Nguyen, Isabelle Kleiner

\section{- To cite this version:}

Thuy Nguyen, Christina Dindic, Wolfgang Stahl, Ha Vinh Lam Nguyen, Isabelle Kleiner. 14 N Nuclear quadrupole coupling and methyl internal rotation in the microwave spectrum of 2-methylpyrrole. Molecular Physics, 2020, The 26th Colloquium on High-Resolution Molecular Spectroscopy, 118 (11), pp.1668572. 10.1080/00268976.2019.1668572 . hal-03360589

\section{HAL Id: hal-03360589 \\ https://hal.science/hal-03360589}

Submitted on 30 Sep 2021

HAL is a multi-disciplinary open access archive for the deposit and dissemination of scientific research documents, whether they are published or not. The documents may come from teaching and research institutions in France or abroad, or from public or private research centers.
L'archive ouverte pluridisciplinaire HAL, est destinée au dépôt et à la diffusion de documents scientifiques de niveau recherche, publiés ou non, émanant des établissements d'enseignement et de recherche français ou étrangers, des laboratoires publics ou privés. 


\title{
${ }^{14} \mathrm{~N}$ nuclear quadrupole coupling and methyl internal rotation in the microwave
}

\section{spectrum of 2-methylpyrrole}

\author{
Thuy Nguyen, ${ }^{\mathrm{a}}$ Christina Dindic, ${ }^{\mathrm{b}}$ Wolfgang Stahl, ${ }^{\mathrm{b}}$ Ha Vinh Lam Nguyen, ${ }^{\mathrm{a}^{*}}$ and
}

Isabelle Kleiner ${ }^{\mathrm{a}}$

${ }^{a}$ Laboratoire Interuniversitaire des Systèmes Atmosphériques (LISA), CNRS UMR 7583, Université Paris-Est Créteil, Université de Paris, Institut Pierre Simon Laplace (IPSL), 61 avenue du Générale de Gaulle, F-94010 Créteil, France

${ }^{b}$ Institute of Physical Chemistry, RWTH Aachen University, Landoltweg 2, D-52074

Aachen, Germany

*Corresponding author: Ha Vinh Lam Nguyen

Laboratoire Interuniversitaire des Systèmes Atmosphériques (LISA), UMR CNRS 7583, Université

Paris-Est-Créteil, Université de Paris, Institut Pierre Simon Laplace (IPSL), Créteil, France

Phone: 0033182392044

Email: lam.nguyen@lisa.u-pec.fr 


\section{${ }^{14} \mathrm{~N}$ nuclear quadrupole coupling and methyl internal rotation in the}

\section{microwave spectrum of 2-methylpyrrole}

Using two molecular jet Fourier transform microwave spectrometers, the rotational spectrum of 2methylpyrrole was recorded in the frequency range from 2 to $40 \mathrm{GHz}$. From the torsional splittings due to the internal rotation of the methyl group a barrier height of $279.7183(26) \mathrm{cm}^{-1}$ was deduced. Because of the ${ }^{14} \mathrm{~N}$ nucleus, all lines show a quadrupole hyperfine structure. The microwave spectra were analyzed using the XIAM and BELGI- $C_{s}$-hyperfine codes. The XIAM code enabled us to reproduce the whole data set with a root-mean-square deviation of $5.6 \mathrm{kHz}$ while the $B E L G I-C_{s^{-}}$ hyperfine code could provide a better root-mean-square almost by a factor of 2 compared to that of $X I A M$. The experimental results were complemented by quantum chemical calculations. The values of the methyl torsional barrier and the ${ }^{14} \mathrm{~N}$ nuclear quadrupole coupling constants are discussed and compared with other methyl substituted pyrroles as well as other aromatic five-membered rings.

Keywords: 2-methylpyrrole, microwave spectrum, internal rotation, nuclear hyperfine.

$$
<<<\text { Graphical abstract is approximately here }>>
$$

\section{Introduction}

For many years, the phenomenon of internal rotation has been a subject of considerable interest to both chemists and physicists. Studies of potential functions, barrier heights, stability of rotational isomers, and ring conformations provide basic information for testing and improving methods to understand the effects of internal rotation. Quantum chemical calculations together with molecular jet Fourier transform microwave (MJ-FTMW) spectroscopy allow us to obtain the torsional potential with high accuracy.

Due to steric and electronic interactions, the torsional potential of methyl groups attached to an aromatic compound are often hard to predict intuitively, while results from quantum chemical calculations are still rather not sufficiently accurate. Many investigations have been carried out on such aromatic systems, especially heterocyclic five-membered rings, to determine the methyl barrier heights, i.a. 2-methylthiazole $\left(34.9 \mathrm{~cm}^{-1}\right)$ [1], 4-methylisothiazole $\left(105.8 \mathrm{~cm}^{-1}\right)$ [2], 2,5dimethylthiophene $\left(248.0 \mathrm{~cm}^{-1}\right)$ [3], 2-acetyl-5-methylfuran $\left(369.8 \mathrm{~cm}^{-1}\right.$ for the trans conformer and $356.5 \mathrm{~cm}^{-1}$ for the cis conformer) [4], and 2,5-dimethylfuran $\left(439.2 \mathrm{~cm}^{-1}\right)$ [5]. From those 
studies it is obvious that the torsional potentials of methyl groups attached to planar aromatic rings vary in a wide range in both, shape and height.

Pyrroles are nitrogen containing five-membered ring systems which possess unique organoleptic properties [6]. Some pyrroles are used as flavor additives. In the 1960s, pyrroles became known to represent a minor class of potentially significant flavor-associated compounds that occur naturally in foods. Pyrrole and the methyl substituted compound, 2-methylpyrrole (2MP), are found in volatile compounds from fried chicken [7]. Pyrrole also provides the key structural subunit for many of the most important biological molecules, such as heme and chlorophyll. Pyrrole and its derivatives exhibit wide range of biological and pharmaceutical activities, i.a. antibacterial, anti-fungal, anti-viral, anti-inflammatory, anti-cancer and antioxidant activity [8].

From a spectroscopic point of view, 2MP contains a methyl group which undergoes internal rotation and a ${ }^{14} \mathrm{~N}$ nucleus which causes a nuclear quadrupole hyperfine structure. Within the scope of this work, a combination of quantum chemical calculations and MJ-FTMW spectroscopy was used to determine the shape of the potential function and the barrier to internal rotation. The quadrupole hyperfine structure yielded information on the electric field gradient at the site of the ${ }^{14} \mathrm{~N}$ nucleus and consequently on the nature of its chemical bonds.

\section{Quantum chemical calculations}

To facilitate the spectral assignment, initial values of the rotational constants, the torsional potential, and the ${ }^{14} \mathrm{~N}$ nuclear quadrupole coupling constants (NQCCs) were calculated by quantum chemical methods using the GAUSSIAN16 program package [9].

\section{Geometry optimizations}

The molecular geometry of 2MP was optimized at different levels of theory with various combinations of the MP2, B3LYP, M06-2X, and CCSD methods with different basis sets to check for the convergence and to find out the level of theory which yields rotational constants in best agreement with the experimental values. A selection of the calculations is presented in Table 1. The predicted rotational constants are given along with the dipole moment components and the angle between the inertial principal $a$ axis and the methyl rotor axis. For comparison, the experimental rotational constants are also shown. A full list with all calculations is given in Table 
S2 in the supplementary online material. The molecular geometry as optimized at the MP2/ccpVDZ level of theory is shown in Figure 1.

$<<$ Table 1 is approximately here >>

It should be noted that the internal rotor axis is almost parallel to the principal $a$ axis (see also the value of the angle $\angle(i, a)$ in Table 1). At equilibrium, the dihedral angle $\alpha=\angle\left(\mathrm{C}_{3}, \mathrm{C}_{2}, \mathrm{C}_{6}, \mathrm{H}_{11}\right)$ is $0^{\circ}$, i.e. the methyl group is staggered with respect to the nitrogen atom.

$<<$ Figure 1 is approximately here $>>$

\section{Torsional potential of the methyl group}

To obtain the barrier height to internal rotation and the shape of the potential function, geometry optimizations at the MP2/cc-pVDZ level of theory were carried out while the dihedral angle $\alpha$ was varied in steps of $10^{\circ}$. The resulting potential curve is given in Figure S1 in the supplementary online material. The potential was parameterized by a symmetry-adapted Fourier series with the Fourier coefficients given in Table S3 in the supplementary online material.

The torsional potential of 2MP displays the typical threefold shape caused by the symmetry of the methyl group. The potential consists of a $V_{3}$ value of $255.24 \mathrm{~cm}^{-1}$ with a $V_{6}$ contribution of 36.16 $\mathrm{cm}^{-1}$.

\section{${ }^{14} \mathrm{~N}$ nuclear quadrupole coupling constants (NQCCs)}

In many previous studies on nitrogen containing molecules [10,11], the method of calculating ${ }^{14} \mathrm{~N}$ NQCCs given by Bailey [12] turned out to be very reliable and was also applied in this work. At first, the molecular structure of 2MP was optimized at the MP2/cc-pVDZ level of theory. For this optimized structure, the electric field gradient tensor of the ${ }^{14} \mathrm{~N}$ nucleus in $2 \mathrm{MP}$ was computed at the B3PW91/6-311+G(d,p) level of theory, as recommended for $\pi$-conjugated system [13]. Using the calibration factor $\mathrm{eQ} / \mathrm{h}=4.599 \mathrm{MHz} / \mathrm{a}$.u. [13], the quadrupole coupling tensor with the diagonal elements $\chi_{a a}=1.331 \mathrm{MHz}, \chi_{b b}=1.665 \mathrm{MHz}$, and $\chi_{c c}=-2.996 \mathrm{MHz}$, as well as the off-diagonal element $\chi_{a b}=0.091 \mathrm{MHz}$ was obtained. Due to the symmetry of the molecule $\chi_{a c}$ and $\chi_{b c}$ are zero. 


\section{Experiment}

\section{Measurements}

2MP was purchased from abcr GmbH, Karlsruhe, Germany, with a stated purity of $95 \%$ and was used without further purification. A piece of pipe cleaner was soaked with the substance and inserted into a stainless steel tube placed upstream the nozzle. Helium, which was used as carrier gas, flowed over the substance at a pressure of 200-250 kPa.

All spectra were recorded using two MJ-FTMW spectrometers operating in the frequency ranges from 2.0 to $26.5 \mathrm{GHz}$ [14] and from 26.5 to $40.0 \mathrm{GHz}$ [15]. At first, a broadband scan was recorded from 12.0 to $14.9 \mathrm{GHz}$. The lines observed in the scan were remeasured at higher resolution. All lines show a hyperfine structure due to the nuclear quadrupole coupling of the ${ }^{14} \mathrm{~N}$ nucleus. A typical spectrum is given in Figure 2.

\section{$<<$ Figure 2 is approximately here $>>$}

\section{Spectral assignment}

At the beginning of the assignment we predicted the spectrum with the XIAM code [16] using the rotational constants, the $V_{3}$ potential, and the angle between the internal rotor axis and the inertial $a$ axis obtained by ab initio calculations at the MP2/cc-pVDZ level of theory, and neglected

the quadrupole hyperfine splittings due to the ${ }^{14} \mathrm{~N}$ nucleus. The predicted dipole moment components are $\left|\mu_{a}\right|=1.07 \mathrm{D},\left|\mu_{b}\right|=1.79 \mathrm{D}$ and $\left|\mu_{c}\right|=0.00 \mathrm{D}$ (see Table 1). Therefore, A species $c$ type transitions were not expected to be observed in the spectrum. By comparing the broadband scan and the predicted spectrum the $A$ and $E$ torsional components of the $2_{11} \leftarrow 1_{10}, 3_{03} \leftarrow 2_{12}, 3_{21}$ $\leftarrow 3_{12}$, and $4_{21} \leftarrow 4_{13}$ transitions could be identified. The linear combinations of the rotational constants $B_{K}=A-0.5(B+C), B_{J}=0.5(B+C), \mathrm{B}_{-}=0.5(B-C)$ and the $V_{3}$ potential were fitted, which enabled us to predict all other transitions with sufficient accuracy. Only one line in the scan region remained unassigned, which later turned out to be the $c$-type transition $1_{10} \leftarrow 0_{00}$ of the $\mathrm{E}$ species, which is nominally forbidden in the semi-rigid rotor approximation.

Afterwards, all lines were remeasured at high resolution. In this step, the quadrupole coupling effect was taken into account. The values of the NQCCs obtained by quantum chemical 
calculations were used to predict the hyperfine patterns, which fairly matched those of the experimental spectra. Due to spin-rotation and spin-spin interactions, some transitions show additional splittings of the order of $10 \mathrm{kHz}$. In those cases, the average of the individual components was taken.

\section{Results and discussion}

Results of the fits

Two global fits of 2MP with 62 A species and 67 E species lines with a total number of 359


measurement accuracy is about $3.0 \mathrm{kHz}$ for all lines. The root-mean-square (rms) deviations are $5.6 \mathrm{kHz}$ and $3.1 \mathrm{kHz}$, respectively. The fit results are given in Table 2, the frequency list is available

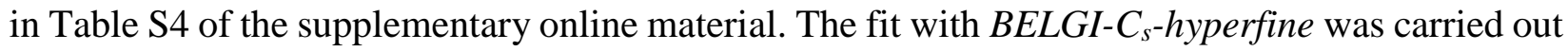
in the rho axis system with the parameters defined in this coordinate system are given in Table 3. For comparison with the XIAM results, some parameters were converted to the principal axis system (also presented in Table 2).

\section{$<<$ Table 2 is approximately here $>>$}

With the XIAM code, the three linear combination of rotational constants, five quartic centrifugal distortion constant $\Delta_{J}, \Delta_{J K}, \Delta_{K}, \delta_{J}, \delta_{K}$, the ${ }^{14} \mathrm{~N}$ NQCCs $\chi_{a a}, \chi_{b b}-\chi_{c c}$, as well as the barrier to internal rotation $V_{3}$, the angle $\angle(i, a)$ between the $a$ axis and the internal rotor axis and two higher order terms $D_{p i 2 J}, D_{p i 2 K}$ enabled us to reproduce the experimental spectra to a $r m s$ deviation of $5.6 \mathrm{kHz}$. In order to treat molecules containing one methyl rotor and one nitrogen nucleus, the BELGI code

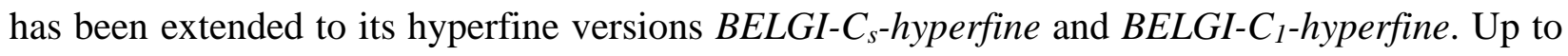
now, three molecular systems have been successfully treated by these codes, which are $N$-tertbutylacetamide $\left(\mathrm{C}_{\mathrm{s}}\right)$ [17], $N$-ethylacetamide $\left(\mathrm{C}_{1}\right)$ [10] and 3-nitrotoluene $\left(\mathrm{C}_{\mathrm{s}}\right)$ [18]. In this work, the

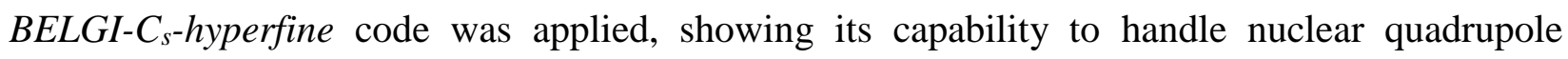
coupling in the presence of internal rotation.

$$
<<\text { Table } 3 \text { is approximately here }>>
$$

\section{Discussion}


The rotational constants from the XIAM and the BELGI-C $C_{s^{-}}$hyperfine fits are in good agreement, however, they do not agree within their standard errors. This is due to the fact that different sets of parameters were used, and that the conversion of some RAM parameters to PAM parameters is not unique and introduces some errors. It turned out that the MP2 method as well as the DFT method with the B3LYP functional in combination with Grimme's dispersion correction and BeckeJohnson damping [19] yielded a good agreement with the experimental rotational constants for most sufficiently large basis sets. Rotational constants predicted with Truhlar's M06-2X method [20] are in general further off from the experimental values. Comparison between the rotational constants obtained from XIAM with those from ab initio calculations at the MP2/cc-pVDZ level of theory shows deviations of $1.12 \%$ for $A, 0.99 \%$ for $B$, and $1.05 \%$ for $C$ (with respect to the experimental values). A better agreement is not expected at the level of theory in use, because the experimental constants observed in the vibrational ground state are not directly comparable with the equilibrium values obtained from the ab initio calculations. From the results given in Table S2, the values of the rotational constants predicted at our most time-consuming calculations CCSD/6$311++\mathrm{G}(\mathrm{d}, \mathrm{p})$ are very close to the experimental values. Similar results can be achieved using a combination of the $6-31+\mathrm{G}(\mathrm{d}, \mathrm{p})$ or $6-31++\mathrm{G}(\mathrm{d}, \mathrm{p})$ basis set with the B3LYP or MP2 method, probably due to error compensation. From our experience, the same kind of error compensation always occurs at the same level of theory. Therefore, these levels might be chosen to predict reliable rotational constants to start the spectral assignment of future investigations on related methyl substituted pyrroles.

The parameters associated with the internal rotation, the $V_{3}$ potential and the angle between the principal $a$ axis and the internal rotor axis $\angle(i, a)$, obtained from the XIAM and BELGI programs agree satisfactory, while the predicted $V_{3}$ potential is $8.8 \%$ lower than the experimental value. This deviation is rather large, however, it is in the expected range for quantum chemical calculations at the MP2/cc-pVDZ level of theory. In contrast to the geometry parameters, the calculations of the $V_{3}$ potential strongly depend on the method and basis set and a convergence is hard to achieve. Furthermore, the effects of zero point vibrations are known to influence the calculated value. Though the calculated potential also contains contributions of $V_{6}$ and higher order terms, they are assumed to be negligible in the potential function fitted with the current experimental data. With only transitions in the torsional ground state, it is impossible to test the validity of this assumption, as $V_{6}$ cannot be determined. 
The ${ }^{14} \mathrm{~N}$ NQCCs obtained from the XIAM and the BELGI fits agree within the standard errors. The quantum chemical results obtained at the B3PW91/6-311+G(d,p)//MP2/cc-pVDZ level agree within $0.3 \%$ for $\chi_{a a}$ and $-6.9 \%$ for $\chi_{b b}-\chi_{c c}$ (with respect to the experimental values). In the principal axis system, an experimental value for $\chi_{a b}$ cannot be obtained because it is associated with the expectation value of $\left\{\mathrm{P}_{\mathrm{a}}, \mathrm{P}_{\mathrm{b}}\right\}$ which is zero in the case of the A species and which cannot be determined well from the E species at rather high barriers such as $280 \mathrm{~cm}^{-1}$. If we calculate the same quantity in RAM and back-transform it to PAM, we will not be able to acquire $\chi_{a b}$. Particularly in case of 2MP, the off-diagonal elements of the nuclear quadrupole coupling tensor


was not possible.

Some results obtained for $2 \mathrm{MP}$ are compared with those of other five-membered heterocycles in Figure 3.

$$
<<\text { Figure } 3 \text { is approximately here }>>
$$

The $V_{3}$ potential varies in a wide range from $34 \mathrm{~cm}^{-1}$ for 2-methylthiazole (6) [1], $106 \mathrm{~cm}^{-1}$ for 4-methylisothiazole (8) [2], $252 \mathrm{~cm}^{-1}$ for 2-methyloxazole (7) [21] to $280 \mathrm{~cm}^{-1}$ for $2 \mathrm{MP}(\mathbf{5})$. The $V_{3}$ potential is due to symmetry strictly $0 \mathrm{~cm}^{-1}$ for molecules with a $\mathrm{C}_{2 \mathrm{v}}$ symmetric frame and an internal rotor of $\mathrm{C}_{3 \mathrm{v}}$ symmetry. Only a small $V_{6}$ term is found in the cases of toluene [22], nitromethane [23, 24], and $N$-methylpyrrole [25]. If the frame symmetry is lowered from $\mathrm{C}_{2 \mathrm{v}}$ to $\mathrm{C}_{\mathrm{s}}$, then a $V_{3}$ contribution is observed, depending on the local asymmetry due to steric or electronic effects. In 2-methylthiazole (6) the nitrogen and sulfur atoms have similar effects on the methyl rotor and only a very low $V_{3}$ potential arises. In 4-methylisothiazole (8) a similar situation also leads to a rather low barrier of $106 \mathrm{~cm}^{-1}$. In the title compound $2 \mathrm{MP}(5)$ the environment of the methyl group with a $\mathrm{NH}$ group on one side and a carbon atom on the other side is rather asymmetric which results in a much higher barrier. We note that such intuitive interpretations should be taken with caution because in aromatic systems electronic effects are easily propagated through the $\pi$ system of the ring and affect the barrier height.

The aromaticity is associated with a planar structure of the $\pi$ electron system. A direct measure for planarity is the inertial defect $\Delta_{c}=I_{c}-I_{a}-I_{b}$ with the principal moments of inertia $I_{a}$, $I_{b}, I_{c}$ is calculated for all compounds in Figure 3. In the case of the non-methylated systems inertial defects of $0.017,0.074,0.056$, and $0.076 \mathrm{u}^{2}$ are found for pyrrole (1) [26], thiazole (2) [27], 
oxazole (3) [28], and isothiazole (4) [29], respectively. The deviation from zero can be explained by the zero point vibrations of the rings. If one methyl group is attached to the ring, the out-ofplane hydrogen atoms of the methyl group cause an inertial defect close to $3.2 \mathrm{u}^{2}$. This is in agreement with the values of $-3.223,-3.108,-3.127$, and $-3.012 \mathrm{u}^{2}$ of $2 \mathrm{MP}(5)$, 2-methylthiazole (6), 2-methyloxazole (7), and 4-methylisothiazole (8), respectively.

In all systems given in Figure 3 the principal $c$ axis perpendicular to the ring plane is collinear with one principal axis of the coupling tensor. Therefore, the $\chi_{c c}$ element of the ${ }^{14} \mathrm{~N}$ quadrupole coupling tensor can be directly compared. In pyrrole (1) and 2MP (5), the values of $\chi_{c c}$ are very similar but have a different sign than in all other heterocycles (2-4) and (6-8). The reason is, that the two groups exhibit a very different bond situation at the nitrogen atom which causes different electric field gradients at the site of the nitrogen nucleus. The electron configuration of nitrogen is $[\mathrm{He}] 2 \mathrm{~s}^{2} 2 \mathrm{p}^{3}$. In all compounds of Figure 3, three $\mathrm{sp}^{2}$ hybrid orbitals are formed, two of which are used to form the $\sigma$ bonds to the neighboring atoms. One p orbital remains and becomes part of the $\pi$ electron system. As shown in Figure 4, in the case of pyrrole three of five nitrogen electrons are needed in three $\mathrm{sp}^{2}$ orbitals to form the two $\mathrm{N}-\mathrm{C}$ bonds and one $\mathrm{N}-\mathrm{H}$ bond (not illustrated). The other two electrons occupy the p orbital (illustrated in red) and contribute to the $\pi$ electron system. Altogether, there are $6 \pi$ electrons which, according to the $4 n+2$ rule, makes pyrrole an aromatic compound.

$<<$ Figure 4 is approximately here $>>$

In the other heterocycles, the situation is quite different. For oxazole, two $\mathrm{sp}^{2}$ orbitals of the nitrogen atom with one electron each form the bonds to the neighboring atoms (not illustrated). The third $\mathrm{sp}^{2}$ orbital is occupied by an electron lone pair (illustrated in black). Only one electron remains in the p orbital (illustrated in red) contributing to the $\pi$ electron system. It should be noted that in this group of molecules a sulfur or an oxygen atom is needed to donate two electrons for their $\mathrm{p}$ orbital to fulfill the condition for an aromatic compound (6 electrons in the $\pi$ system). Similar considerations apply also to thiazole and isothiazole.

In the case of pyrrole, the effect of methylation on $\chi_{c c}$ is small. Despite the well-known $+\mathrm{I}$ effect [30] of methyl groups, only a small change in the field gradient tensor is observed. The 
values of $\chi_{c c}$ of pyrrole (1) and 2MP (5) are -2.704 and $-2.846 \mathrm{MHz}$, respectively. Similar small effects are observed upon methylation of thiazole (4), oxazole (6), and isothiazole (8).

\section{Conclusion}

The methyl torsional fine structure and the quadrupole hyperfine structure in the rotational spectrum of 2MP could be fully resolved using two molecular jet Fourier transform microwave spectrometers operating in the frequency range from 2 to $40 \mathrm{GHz}$. All observed transitions were analyzed and fitted with the programs XIAM and BELGI-C$C_{s^{-}}$hyperfine, whereby the BELGI-C $C_{s^{-}}$ hyperfine code enabled us to reproduce the whole data set close to measurement accuracy. The spectroscopic work was supplemented by quantum chemical calculations.

The methyl group undergoes internal rotation with a $V_{3}$ hindering potential of $279.7183(26) \mathrm{cm}^{-1}$. The quadrupole coupling constants of the ${ }^{14} \mathrm{~N}$ nucleus were determined with very high accuracy. Calculations of the electric field gradient tensor with Bailey's method yielded nuclear coupling constants in good agreement with the experimental values.

\section{Disclosure statement}

No potential conflict of interest was reported by the authors.

\section{Funding}

T. N. thanks the Doctoral School of Environmental Science of Île-de-France (DS 129) for a Ph.D grant. Simulations were performed with computing resources granted by RWTH Aachen University under project rwth0369. W.S. thanks the Université Paris-Est for an invited researcher grant which enabled him to work at the Université Paris-Est Créteil. This work was supported by the Agence Nationale de la Recherche ANR (project ID ANR-18-CE29-0011).

\section{Acknowledgement}


I.K., H.V.L.N., and T.N. thank the DIM Qi2 for supporting the organization of the Journées de Spectroscopie Moléculaire (JSM) in Créteil where T.N. presented a poster with the results. C.D. thanks the DIM Qi2 for supporting her trip to the JSM.

\section{References}

[1] J.-U. Grabow, H. Hartwig, N. Heineking, W. Jäger, H. Mäder, H.W. Nicolaisen, W. Stahl, J. Mol. Struct. 612, 349 (2002).

[2] H.W. Nicolaisen, J.-U. Grabow, N. Heineking, W. Stahl, Z. Naturforsch. 46a, 635 (1991).

[3] V. Van, W. Stahl, H.V.L. Nguyen, Phys. Chem. Chem. Phys, 17, 32111 (2015).

[4] V. Van, W. Stahl, H.V.L. Nguyen, ChemPhysChem 17, 3223 (2016).

[5] V. Van, J. Bruckhuisen, W. Stahl, V. Ilyushin, H.V.L. Nguyen, J. Mol. Spectrosc. 343, 121 (2017).

[6] J.A. Maga, J. Agric. Food Chem. 29, 691 (1981).

[7] J. Tang, Q.Z. Jin, G.-H. Shen, C.T. Ho, S.S. Chang, J. Agric. Food Chem. 31, 1287 (1983).

[8] R. Kaur, V. Rani, V. Abbot, Y. Kapoor, D. Konar, K. Kumar, J. Pharm. Chem. Chem. Sci. 1, 17 (2017).

[9] M.J. Frisch, G.W. Trucks, H.B. Schlegel, G.E. Scuseria, M.A. Robb, J.R. Cheeseman, G. Scalmani, V. Barone, G.A. Petersson, H. Nakatsuji, X. Li, M. Caricato, A.V. Marenich, J. Bloino, B.G. Janesko, R. Gomperts, B. Mennucci, H.P. Hratchian, J.V. Ortiz, A.F. Izmaylov, J.L. Sonnenberg, D. Williams-Young, F. Ding, F. Lipparini, F. Egidi, J. Goings, B. Peng, A. Petrone, T. Henderson, D. Ranasinghe, V.G. Zakrzewski, J. Gao, N. Rega, G. Zheng, W. Liang, M. Hada, M. Ehara, K. Toyota, R. Fukuda, J. Hasegawa, M. Ishida, T. Nakajima, Y. Honda, O. Kitao, H. Nakai, T. Vreven, K. Throssell, J.A. Montgomery, Jr., J.E. Peralta, F. Ogliaro, M.J. Bearpark, J.J. Heyd, E.N. Brothers, K.N. Kudin, V.N. Staroverov, T.A. Keith, R. Kobayashi, J. Normand, K. Raghavachari, A.P. Rendell, J.C. Burant, S.S. Iyengar, J. Tomasi, M. Cossi, J.M. Millam, M. Klene, C. Adamo, R. Cammi, J.W. Ochterski, R.L. Martin, K. Morokuma, O. Farkas, J.B. Foresman, D.J. Fox, Gaussian 16, Revision B.01, Gaussian, Inc., Wallingford CT, 2016.

[10] R. Kannengießer, M.J. Lach, W. Stahl, H.V.L. Nguyen, ChemPhysChem. 16, 1906 (2015).

[11] R. Kannengießer, S. Klahm, H.V.L. Nguyen, A. Lüchow, W. Stahl, J. Chem. Phys. 141, 204308 (2014).

[12] W.C. Bailey, Chem. Phys. 252, 57 (2000). 
[13] R. Kannengießer, W. Stahl, H.V.L. Nguyen, W.C. Bailey, J. Mol. Spectrosc. 317, 50 (2015).

[14] J.-U. Grabow, W. Stahl, H. Dreizler, Rev. Sci. Instrum. 67, 4072 (1996).

[15] I. Merke, W. Stahl, H. Dreizler, Z. Naturforsch. 49a, 490 (1994).

[16] H. Hartwig, H. Dreizler, Z. Naturforsch. 51a, 923 (1996).

[17] R. Kannengießer, W. Stahl, H.V.L. Nguyen, I. Kleiner, J. Phys. Chem. A 120, 3992 (2016).

[18] A. Roucou, I. Kleiner, M. Goubet, S. Bteich, G. Mouret, R. Bocquet, F. Hindle, W.L. Meerts, A. Cuisset, ChemPhysChem. 19, 1056 (2018).

[19] E. Caldeweyher, C. Bannwarth, S. Grimme, J. Chem. Phys. 147, 034112 (2017).

[20] Y. Zhao, D.G. Truhlar, Theor. Chem. Acc. 120, 215 (2008).

[21] E.R.L. Fliege, Z. Naturforsch. 45a, 911 (1990).

[22] V. V. Ilyushin, E. A. Alekseev, Z. Kisiel, L. Pszczółkowski, J. Mol. Spectrosc. 339, 31 (2017). [23] F. Rohart, J. Mol. Spectrosc. 57, 301 (1975).

[24] V. V. Ilyushin, J. Mol. Spectrosc. 345, 64 (2018).

[25] J. Makarewicz, S. Huber, B. Brupbacher-Gatehouse, A. Bauder, J. Mol. Struct, 612, 117 (2002).

[26] L. Nygaard, J.T. Nielsen, J. Kirchheiner, G. Maltesen. J.R. Andersen, G.O. Sørensen, J. Mol. Struct. 3, 491 (1969).

[27] L. Nygaard, E. Asmussen, J.H. Høg, R. C. Maheshwari, C.H. Nielsen, I.B. Petersen, J. Rastrup-Andersen, G.O. Sørensen, J. Mol. Struct. 8, 225 (1971).

[28] A. Kumar, J. Sheridan, O.L. Stiefvater, Z. Naturforsch. 33a, 145 (1978).

[20] J.H. Griffiths, A. Wardley, V.E. Williams, N.L. Owen, J. Sheridan, Nature 216, 1301 (1967).

[30] C.K. Ingold, J. Chem. Soc. 1120 (1933). 
Table 1. The rotational constants (in $\mathrm{MHz}$ ), the angle between the inertial principal $a$ axis and the internal rotor axis $i$ (in degree), and the dipole moment components (in Debye) obtained by optimizations of the molecular geometry of $2 \mathrm{MP}$ at various levels of theory.

\begin{tabular}{lccccccc}
\hline & $A$ & $B$ & $C$ & $\angle(i, a)$ & $\left|\mu_{a}\right|$ & $\left|\mu_{b}\right|$ & $\left|\mu_{c}\right|$ \\
\hline MP2/6-311+G(d,p) & 8536.0 & 3417.4 & 2478.4 & 2.82 & 1.16 & 1.72 & 0.00 \\
MP2/6-311++G(d,p) & 8533.9 & 3419.1 & 2479.1 & 2.80 & 1.16 & 1.71 & 0.00 \\
B3LYP-D3/6-311+G(d,p) & 8594.5 & 3427.0 & 2488.1 & 2.87 & 1.09 & 1.67 & 0.00 \\
B3LYP-D3/6-311++G(d,p) & 8595.3 & 3427.0 & 2488.1 & 2.86 & 1.09 & 1.66 & 0.00 \\
MP2/cc-pVDZ & 8462.7 & 3398.5 & 2462.7 & 2.75 & 1.07 & 1.79 & 0.00 \\
MP2/cc-pVTZ & 8607.6 & 3446.9 & 2499.5 & 2.77 & 1.08 & 1.73 & 0.00 \\
B3LYP-D3/ cc-pVDZ & 8535.3 & 3415.7 & 2477.7 & 2.80 & 1.03 & 1.79 & 0.00 \\
B3LYP-D3/ cc-pVTZ & 8639.7 & 3444.5 & 2500.9 & 2.84 & 1.02 & 1.69 & 0.00 \\
CCSD/6-311++G(d,p) & 8549.4 & 3413.6 & 2477.6 & 2.93 & 1.13 & 1.69 & 0.00 \\
Experimental & 8559.0 & 3432.5 & 2488.9 & 2.00 & & & \\
\hline \hline
\end{tabular}



Table 2. Molecular parameters of $2 \mathrm{MP}$ in the inertial principal axis system obtained from fits with $X I A M$ and BELGI-C s $^{-}$hyperfine.

\begin{tabular}{|c|c|c|c|c|}
\hline Par. ${ }^{a}$ & Unit & Fit XIAM & Fit $B E L G I^{\mathrm{b}}$ & $a b$ initio $^{c}$ \\
\hline$A$ & $\mathrm{MHz}$ & $8558.954(44)$ & $8569.751(34)$ & 8462.7 \\
\hline$B$ & $\mathrm{MHz}$ & $3432.5127(87$ & $3432.832(38)$ & 3398.5 \\
\hline$C$ & $\mathrm{MHz}$ & $2488.8717(87$ & $2489.1935(69)$ & 2462.7 \\
\hline$\Delta_{J}$ & $\mathrm{kHz}$ & $0.2354(19)$ & $0.2391(11)$ & 0.2236 \\
\hline$\Delta_{J K}$ & $\mathrm{kHz}$ & $1.397(10)$ & & 1.4044 \\
\hline$\Delta_{K}$ & $\mathrm{kHz}$ & $0.790(30)$ & & 0.5694 \\
\hline$\delta_{J}$ & $\mathrm{kHz}$ & $0.06467(77)$ & & 0.0618 \\
\hline$\delta_{K}$ & $\mathrm{kHz}$ & $0.401(18)$ & & 0.4222 \\
\hline$F_{o}$ & $\mathrm{GHz}$ & $158^{d}$ & & 158.061 \\
\hline$F$ & $\mathrm{GHz}$ & $167.0422^{\mathrm{e}}$ & $167.0422^{f}$ & \\
\hline$V_{3}$ & $\mathrm{~cm}^{-1}$ & $279.7183(26)$ & $278.9946(13)$ & 255.24 \\
\hline$\rho$ & & $0.0541^{\mathrm{e}}$ & $0.0536021(93)$ & \\
\hline$D_{p i 2 J}$ & $\mathrm{kHz}$ & $13.12(92)$ & & \\
\hline$D_{p i 2 K}$ & $\mathrm{MHz}$ & $1.1163(44)$ & & \\
\hline$\chi_{a a}$ & $\mathrm{MHz}$ & $1.3345(20)$ & $1.3342(11)$ & 1.331 \\
\hline$\chi_{b b}-\chi_{c c}$ & $\mathrm{MHz}$ & $4.3599(36)$ & $4.3600(33)$ & 4.661 \\
\hline$\angle(i, a)$ & $\circ$ & $2.002(46)$ & $2.050(24)$ & 2.75 \\
\hline$\angle(i, b)$ & $\circ$ & $87.998(46)$ & $87.950(24)$ & 87.25 \\
\hline$\angle(i, c)$ & $\circ$ & $90.0^{\mathrm{g}}$ & $90.0^{\mathrm{g}}$ & 90 \\
\hline$r m s^{\mathrm{h}}$ & $\mathrm{kHz}$ & 5.6 & 3.1 & \\
\hline$N_{A} / N_{E} / N q^{i}$ & & $62 / 67 / 359$ & $62 / 67 / 359$ & \\
\hline
\end{tabular}

a All parameters refer to the inertial principal axis system. Statistical uncertainties are given as one standard uncertainty in the last digit. Watson's A reduction and $I^{r}$ representation were used. ${ }^{\mathrm{b}}$ Obtained by transformation from the rho axis system to the principal axis system. ${ }^{\mathrm{c}}$ Calculated at the MP2/cc-pVDZ level. ${ }^{\mathrm{d}}$ Fixed to the calculated value. ${ }^{\mathrm{e}}$ Derived parameter. ${ }^{\mathrm{f}}$ Fixed to the value of Fit XIAM. ${ }^{\mathrm{g}}$ Fixed due to symmetry. ${ }^{\mathrm{h}}$ Root-mean-square deviation of the fit. ${ }^{\mathrm{i}}$ Number of $\mathrm{A}$ and $\mathrm{E}$ species transitions as well as number of the hyperfine components. 
Table 3. Spectroscopic constants of $2 \mathrm{MP}$ in the rho axis system obtained using the program

BELGI-C - $^{\text {-hyperfine. }}$

\begin{tabular}{cccc}
\hline Par. $^{\mathrm{a}}$ & Unit & Value & Operator \\
\hline$A$ & $\mathrm{MHz}$ & $8568.696(23)$ & $\mathrm{P}_{\mathrm{a}}{ }^{2}$ \\
$B$ & $\mathrm{MHz}$ & $3433.887(29)$ & $\mathrm{P}_{\mathrm{b}}{ }^{2}$ \\
$C$ & $\mathrm{MHz}$ & $2489.1935(69)$ & $\mathrm{P}_{\mathrm{c}}{ }^{2}$ \\
$D_{a b}$ & $\mathrm{MHz}$ & $73.64(87)$ & $\left\{\mathrm{P}_{\mathrm{a}}, \mathrm{P}_{\mathrm{b}}\right\}$ \\
$\Delta_{J}$ & $\mathrm{kHz}$ & $0.2391(11)$ & $-\mathrm{P}^{4}$ \\
$\Delta_{K}$ & $\mathrm{kHz}$ & $0.736(17)$ & $-\mathrm{P}_{\mathrm{a}}{ }^{4}$ \\
$\Delta_{J K}$ & $\mathrm{kHz}$ & $1.3174(56)$ & $-\mathrm{P}^{2} \mathrm{P}_{\mathrm{a}}{ }^{2}$ \\
$\delta_{J}$ & $\mathrm{kHz}$ & $0.06585(43)$ & $-2 \mathrm{P}^{2}\left(\mathrm{P}_{\mathrm{a}}{ }^{2}-\mathrm{P}_{\mathrm{c}}{ }^{2}\right)$ \\
$\delta_{K}$ & $\mathrm{kHz}$ & $1.000(10)$ & $-\left\{\mathrm{P}_{\mathrm{a}}{ }^{2},\left(\mathrm{P}_{\mathrm{a}}{ }^{2}-\mathrm{P}_{\mathrm{c}}{ }^{2}\right)\right\}$ \\
$\chi_{a a}$ & $\mathrm{MHz}$ & $2.6683(22)$ & \\
$\chi_{b b}$ & $\mathrm{MHz}$ & $3.0258(22)$ & $(1 / 2)(1-\cos 3 \alpha)$ \\
$V_{3}$ & $\mathrm{~cm}-1$ & $278.9946(13)$ & $\mathrm{P}_{\mathrm{a}} \mathrm{P}_{\alpha}$ \\
$\rho$ & $\mathrm{unitless}$ & $0.0536021(93)$ & $\left(\mathrm{P}_{\alpha}-\mathrm{\rho P}_{\mathrm{a}}\right)^{2}$ \\
$F$ & $\mathrm{~cm}-1$ & 5.57193 & $(1-\cos 3 \alpha) \mathrm{P}^{2}$ \\
$F_{v}$ & $\mathrm{MHz}$ & $-0.920(61)$ & \\
$r m s^{c}$ & $\mathrm{kHz}$ & 3.1 & \\
$N_{A} / N_{E} / N_{q}{ }^{d}$ & & $62 / 67 / 359$ & \\
\hline \hline
\end{tabular}

${ }^{a}$ All parameters refer to the rho axis system and cannot be directly compared to those referring to the principal axis system. $\mathrm{P}_{\mathrm{a}}, \mathrm{P}_{\mathrm{b}}, \mathrm{P}_{\mathrm{c}}$ are the components of the overall rotation angular momentum, $P_{\alpha}$ is the angular momentum conjugate to the internal rotation angle $\alpha .\{u, v\}$ is the anti-commutator uv $+\mathrm{vu}$. The product of the parameter and operator from a given row yields the term actually used in the vibration-rotation-torsion Hamiltonian, except for $F, \rho$ and $A$ which occur in the Hamiltonian in the form $F\left(P_{\alpha}-\rho P_{a}\right)^{2}+A P_{a}^{2}$, where $F=\hbar^{2} / 2 r I_{\alpha}$. Statistical uncertainties are shown as one standard uncertainty in the last digits. ${ }^{b}$ Fixed to the value obtained from XIAM fit. ${ }^{\mathrm{c}}$ Root-mean-square deviation of the fit. ${ }^{\mathrm{d}}$ Number of A and E species transitions as well as hyperfine components. The nuclear quadrupole coupling constants are defined in the way that they are by a factor of two greater compared to their definitions in the XIAM program. 


\section{Figure captions}

Figure 1. The molecular geometry of $2 \mathrm{MP}$ optimized at the MP2/cc-pVDZ level of theory. The atom numbering and the $a$ and $b$ inertial principal axis of inertia are given. The hydrogen atom $\mathrm{H}_{13}$ is located behind $\mathrm{H}_{12}$.

Figure 2. A high resolution spectrum of the $4_{14} \leftarrow 3_{03}$ A species transition of 2MP. The Doppler doublets are marked by brackets. The quantum numbers $F^{\prime} \leftarrow F$ are given at the respective hyperfine component. For this spectrum, 153 free induction decays were co-added prior to Fourier transformation.

Figure 3. Comparison of the $V_{3}$ potential, the inertial defect $\Delta_{\mathrm{c}}$, and the ${ }^{14} \mathrm{~N}$ coupling constant $\chi_{\mathrm{cc}}$ of 2MP with those of other five-membered heterocycles. (1) Pyrrole, (2) Thiazole, (3) Oxazole, (4) isothiazole, (5) 2-methylpyrrole, (6) 2-methylthiazole, (7) 2-methyloxazole, (8) 4methylisothiazole.

Figure 4. The $\pi$ electron system in pyrrole and oxazole. 


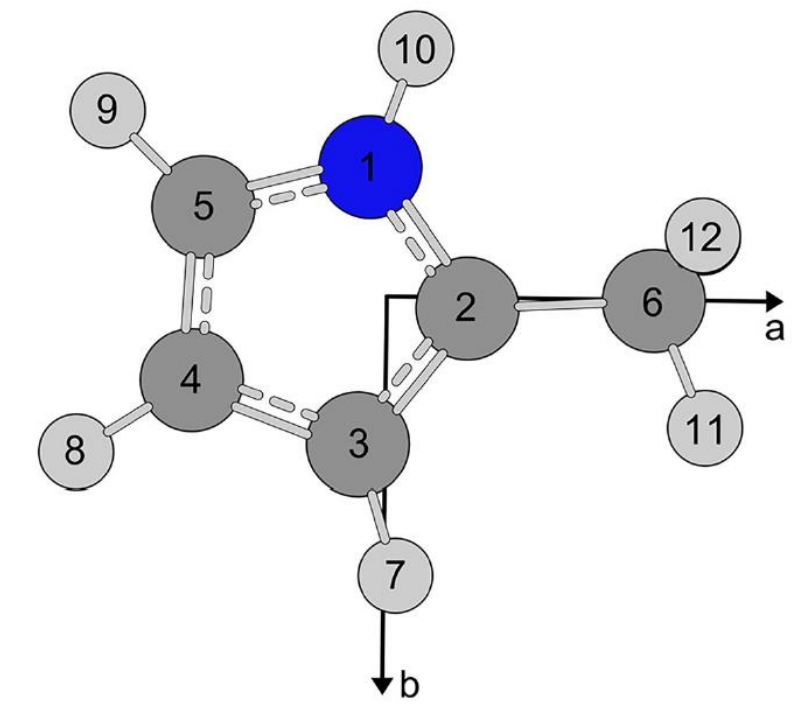

Figure 1. The molecular geometry of $2 \mathrm{MP}$ optimised at the MP2/cc-pVDZ level of theory. The atom numbering and the $a$ and $b$ inertial principal axes of inertia are given. The hydrogen atom $\mathrm{H}_{13}$ is located behind $\mathrm{H}_{12}$.

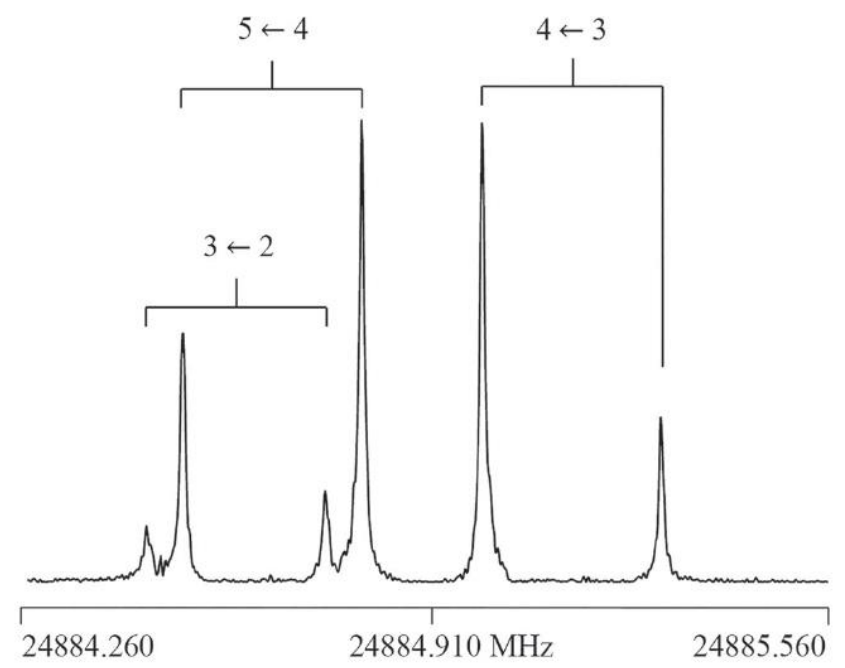

Figure 2. A high resolution spectrum of the $4_{14} \leftarrow 3_{03}$ A species transition of 2MP. The Doppler doublets are marked by brackets. The quantum numbers $F^{\prime} \leftarrow F$ are given at the respective hyperfine component. For this spectrum, 153 free induction decays were co-added prior to Fourier transformation. 




1<smiles>c1cscn1</smiles>

2<smiles>c1cocn1</smiles>

3<smiles>c1cnsc1</smiles>

4

0.076

1.37<smiles>Cc1cnsc1</smiles>

106

$-3.012$

1.459

Figure 3. Comparison of the $V_{3}$ potential, the inertial defect $\Delta_{c}$, and the ${ }^{14} \mathrm{~N}$ coupling constant $\chi_{c c}$ of $2 \mathrm{MP}$ with those of other five-membered heterocycles. (1) Pyrrole, (2) thiazole, (3) oxazole, (4) isothiazole, (5) 2-methylpyrrole, (6) 2-methylthiazole, (7) 2methyloxazole, (8) 4-methylisothiazole.



Pyrrole

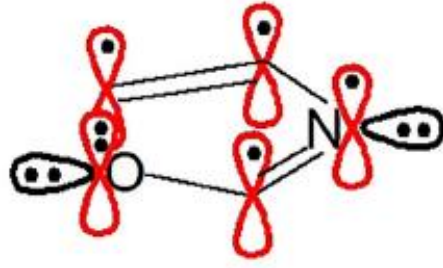

Oxazole

Figure 4. The $\pi$ electron system in pyrrole and oxazole. 